\title{
Ciudad y acceso al hábitat digno: realidades y coyunturas. Reflexiones en torno al Primer Encuentro: "La ciudad que habitamos, la ciudad que queremos"
}

\author{
Esp. Leticia Nora García y Prof. Beatríz Cossio \\ Departamento e Instituto de Geografía (FCH-UNLPam)
}

DOI: http://dx.doi.org/10.19137/huellas-2016-2016

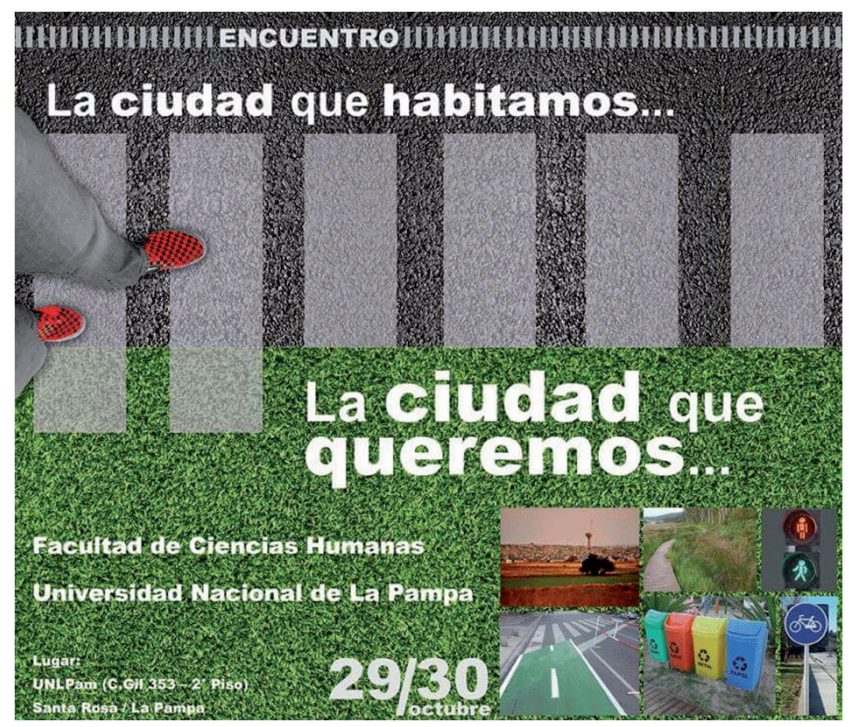

—n Octubre de 2015 se llevó adelante el Primer Encuentro "la ciudad Cque habitamos, la ciudad que queremos" organizado por el Instituto y Departamento de Geografía de la Facultad de Ciencias Humanas de la UNLPam; el INTA y la Asociación de Arquitectos de la Provincia de La Pampa. El sentido que unió voluntades de los diferentes espacios a los que se sumó el Centro de Estudios Ambientales y la Secretaría Nacional de Acceso al Hábitat, fue y sigue siendo el interés, la preocupación y la vocación de pensar en conjunto esta idea de cómo vivir mejor en nuestras ciudades en términos de inclusión. 
Así el tema convocante: el derecho a la ciudad y al acceso a un hábitat digno se puso en dialogo para definir una perspectiva de la ciudad superadora de las tradiciones urbanísticas que han operado históricamente en nuestros entornos urbanos. Este abordaje teórico fue clave para pensar la construcción de un espacio que no solo fuera un evento institucional y académico con el fin de actualizar el conocimiento técnico experto, sino un espacio para la práctica ciudadana que permita incorporar un rol activo de la sociedad en el diseño de las políticas urbanas. El ámbito de la universidad pública se convirtió en el espacio de participación de diferentes actores y componentes de un Estado que debe garantizar el interés público y la conservación de los bienes comunes.

Los invitados especiales, los Arquitectos Eduardo Resse y Raúl Fernandez Wagner fueron convocados por su extensa trayectoria en el urbanismo y la participación en espacios colectivos ${ }^{1}$ para reflexionar y accionar sobre el derecho a la ciudad y el derecho al hábitat digno. Seleccionamos parte de sus exposiciones que refieren puntualmente a la problemática del suelo urbano, gestión y hábitat digno y aportan líneas de análisis sobre la problemática urbana local en contexto.

\section{Políticas públicas, territorio y mercado en ciudades intermedias}

Santa Rosa comparte cuestiones comunes con otras ciudades intermedias en cuanto a procesos de crecimiento y desarrollo advierte Eduardo Resse $^{2}$. En principio, existen variantes comunes que aparecen en ciudades intermedias de Argentina, muchas de América Latina y en el vasto campo de las ciudades pampeanas y propone a partir de ello, algunos presupuestos desde dónde mirar los procesos urbanos.

Es necesario entender a la ciudad como un sistema complejo, pero además como un territorio que está configurado por un entramado de relaciones sociales que lo hacen aún más complejo. Es central en esta idea considerar que cada decisión que se toma tenga en cuenta esta trama. El entramado

1 Habitar Argentina es un espacio conformado por organizaciones, instituciones académicas, movimientos sociales y legisladores, que están trabajando con el objetivo de generar un marco normativo que garantice el derecho a la vivienda, la tierra y al hábitat para todos .

2 Arquitecto, docente de la carrera de Urbanismo en el Instituto del Conurbano de la Universidad Nacional de General Sarmiento, en maestrías y doctorados del país y universidades extranjeras. Director del Área de Derechos Económicos, Sociales y Culturales del Centro de Estudios Legales y Sociales (CELS). 
presenta tres lógicas que actúan en el desarrollo de las ciudades: la lógica política (el lugar del Estado y el conjunto de políticas públicas); la lógica de la acumulación del capital y la lógica de las demandas sociales.

Las tres son lógicas contradictorias, compiten entre sí: las demandas sociales por mejorar el hábitat; los privados por mejorar la renta y el Estado por optimizar recursos. Se generan conflictos, por lo tanto, cada decisión que tomemos en Santa Rosa implica conflicto. Ese conflicto no es una disfunción, la idea no es evitar el conflicto sino construir escenarios democráticos donde expresar esos conflictos de disputa. Estas tres lógicas construyen tres ciudades distintas, aunque conviven a través de vasos comunicantes.

La segunda cuestión que plantea el expositor como desafío en América Latina, es la incorporación de la perspectiva de los Derechos Humanos, no como agregado sino como punto focal. La referencia al Consenso de Montevideo en 2013 pone en escena esta perspectiva en todos los ámbitos de la planificación en territorios de desigualdad. Algunos principios aplicables a políticas de desarrollo territorial con perspectiva de derechos: justicia e igualdad socio espacial, patrones de producción y consumo sostenibles, enfoque de género, interculturalidad, inclusión / cohesión social, prevención de riesgo, participación democrática y acceso a la información, protección ambiental y recursos naturales y seguridad democrática, colaborarían en el fortalecimiento de las políticas públicas.

La tercera consideración que plantea Resse es revisar el concepto de derecho a la ciudad y advierte la necesidad de romper con la dicotomía entre hábitat urbano y rural al proponer junto a otros especialistas la idea de derecho a un hábitat digno. El derecho a un hábitat digno implica un enfoque ampliado e integrado frente al tradicional abordaje segmentado (derecho al agua, a la tierra, a la vivienda, etc.). Por lo tanto, es un derecho colectivo que implica el acceso universal a la tierra, la vivienda, las infraestructuras básicas, los equipamientos sociales, los servicios y los espacios de trabajo y producción, en un marco de respeto de los rasgos culturales y simbólicos de la comunidad y de la preservación del ambiente.

En ese sentido, el autor propone tres postulados para pensar una política de desarrollo territorial. El primero advierte que los mecanismos de mercado no pueden garantizar el uso sostenible y equitativo del suelo ni la reproducción de la ciudad en los mismos términos. La calificación diferencial del suelo en términos del mercado produce un proceso extendido de segregación socioespacial. Entendiendo que el principal producto es la exclusión y la segregación, también es el principal problema y necesariamente la política pública tiene que intervenir. El centro de preocupación de las 
ciudades en Argentina no es la pobreza sino la desigualdad e informalidad. En la informalidad todo resulta mucho más caro, por lo tanto aumenta la desigualdad. La salida de la informalidad es un punto nodal para eliminar la desigualdad, junto a la redistribución de la renta del suelo que se genera todos los días a través de obras públicas. El segundo postulado expresa que la forma de crecimiento de nuestras ciudades es ambientalmente insustentable, socialmente excluyente, económicamente ineficiente y fiscalmente insostenible. Dado que las ciudades viven procesos simultáneos de expansión - colonización del borde rural-; consolidación y densificación- en algunos puntos como avenidas principales, centro, cada uno presenta lógicas diferentes y actores diferentes. Toda la ciudad no es igual, por eso la planificación tiene que atender a cada uno, los instrumentos son distintos, los momentos también.

En general el mayor problema del crecimiento de las ciudades es su fase expansiva con suelo vacante, la especulación inmobiliaria espera valorizaciones futuras a costa del esfuerzo de la comunidad y del Estado. Este proceso de sacar del mercado al suelo urbano, produce necesariamente escasez artificial y aumenta el precio, este mecanismo no está penalizado y además contribuye a extender la ciudad haciéndola insostenible. Hay que pensar en que los problemas económicos de los municipios obedecen a estos mecanismos, es necesario visibilizarlo junto con los procesos de apropiación de excedentes productos del esfuerzo social. En consecuencia señala un tercer postulado vinculado a que las políticas públicas territoriales son fragmentarias, fuertemente tecnocráticas y están regidas por las lógicas del mercado inmobiliario.

En este escenario Eduardo Resse propone instrumentalizar el enfoque de derechos en las políticas de hábitat y abordar, la situación del hábitat rural y del urbano, como problemáticas específicas pero sin perder de vista las interrelaciones y continuidades que las vinculan.

\section{Paradojas del desarrollo urbano en Argentina}

En la conferencia que ofreció Raúl Fernández Wagnerªlanteó la paradoja existente entre el contexto de participación del Estado a la fecha y el aumento de los problemas de acceso al suelo urbano. Existe una crítica situación del desarrollo urbano en Argentina, el país ha duplicado su PBI,

3 Profesor Asociado en el Área de Urbanismo de la Universidad Nacional de General Sarmiento. Consultor en materia de políticas de vivienda y mercados del suelo. 
con un crecimiento sostenido, aun así acrecentó las penurias con el suelo urbano. Estas paradojas ocurren porque necesitamos un Estado y una normativa que opere con el suelo. En Argentina, la tierra fue la base de apropiación de las élites. Esa estructura se forjó a partir de 1800 familias que se quedaron con 42 millones de has. En la matriz de la sociedad argentina está la apropiación de la tierra agraria originalmente y hoy es sobre la tierra urbana, por eso es difícil ponerle límites. Los loteadores hicieron ciudad en el conurbano de Buenos Aires y los servicios de trenes y colectivos fueron las bases de esa urbanización. El loteo era abierto y se vendían los lotes más cercanos a las estaciones, las terminales y reservaba terrenos de frente para valorización a futuro. Había sobreoferta de lotes y la preocupación no era el suelo sino completar la casa.

En los ochenta surgen factores que cambian este proceso. La Ley 8912/77 de uso del suelo de Buenos Aires, prohíbe el loteo sin servicios, de esta maneralos operadores debían hacer loteos con servicios y así terminaron con los loteos populares.

La nueva trama se configura durante la dictadura militar, con la construcción de las autopistas, adoptando un modelo norteamericano basado en el transporte individual. El contexto social vinculado con el empobrecimiento, el agotamiento de las condiciones generales urbanas que sostenían implícitamente las operaciones como el fin de los boletos de trenes subsidiados, el encarecimiento de los boletos de colectivos fueron algunos de los factores concurrentes que se sumaron a la violencia institucional que provocó la erradicación de villas, donde de 224.000 habitantes se redujeron a 16.000 entre 1976 y 1981. Se instala el concepto de que "la ciudad es para quien se la merezca" (Cacciatore, Intendente de la ciudad de Buenos Aires)

Asociado a la crisis con las medidas económicas de este período, se produce el fenómeno de la gran toma de tierras, al sur de Buenos Aires y La Matanza. También aparece asociado a la construcción de las autopistas, el proceso de transformación de los clubes de campo en nuevas formas de urbanizaciones cerradas de la periferia, siguiendo el modelo de suburbanización norteamericana. La situación de ilegalidad no refiere solo a tierras tomadas también a los countries, como refiere el investigador Horacio Torres "no se podía lotear ya que no cedían las calles, eran asentamientos informales de ricos".

Con la sanción del Nuevo Código Civil se le da entidad a los consorcios inmobiliarios. Los impactos van más allá de lo urbano, se dinamizan en cluster de barrios privados que afectan las superficies de frutihorticultura, desplazando familias y con ello la insostenibilidad de la las superficies de agricultura familiar ante el valor que adquiere el suelo. 
En simultáneo aparece otra problemática, la modificación de las superficies de los humedales. Las obras de polderización para barrios cerrados hacen que el Río Luján haya reducido a la mitad su cauce producto de estos rellenamientos. Este tema fue analizado en profundidad por la Geógrafa Patricia Pintos, investigadora de la Universidad Nacional de La Plata.

Los conflictos en el territorio y por el suelo se van acrecentando por esta forma de ocupación. El Nuevo Código Civil reguló la "forma de vivir, de vacacionar y de morir de los ricos": los barrios cerrados, los tiempos compartidos y los cementerios privados. Este Código también redujo los bordes de agua o camino de sirga o área pública de la línea de agua de los lagos, mares y ríos. Eso va a originar una privatización de los bordes que llegan en el caso de lagos y lagunas hasta el borde y aún en el mar. De esta manera, se advierte un claro avance por la vía jurídica o un conjunto de leyes que priorizan el bien privado sobre el común. Los barrios privados dan como resultado una urbanización difusa y no sostenible ambientalmente, hay fragmentación territorial, las calles no son públicas y se afectan los derechos colectivos.

La paradoja es que cuanto más crece la economía y los activos financieros se depositan en el suelo, más se manifiesta la desigualdad espacial. Un análisis de los asentamientos informales realizado por Cravino (UNGS) remite a que, históricamente, el 10\% de la población en la región metropolitana, recurrían al mercado informal para acceder a la vivienda, para el año 2006 el porcentaje se elevó al $60 \%$.

Es destacable que en este periodo, la construcción residencial privada haya representado el $25 \%$ de la inversión total y la mitad del sector de la construcción (CEPAL 2010), y que los valores de las propiedades se hayan incrementado entre seis y diez veces (¡en dólares!).

El crecimiento económico de los últimos años, produce una gran demanda de suelo urbano (en las ciudades y en el periurbano) con valorizaciones extraordinarias del suelo urbano y rural, pero también potencia los procesos especulativos e impacta seriamente en el periurbano de las ciudades, particularmente en ciudades intermedias o pequeñas.

Fernández Wagner expresa además sobre la situación particular de la vivienda en Argentina, a través de distintas operatorias del Estado, de nuevas políticas de acceso a la vivienda única como también de emprendimientos privados, así como también el desarrollo de experiencias de políticas territoriales exitosas aunque no extensivas en el contexto nacional. En ese sentido interesa destacar las iniciativas de Habitar Argentina. Desde este espacio de participación, que comparten ambos especialistas, se ha planteado la necesidad de una Ley de Ordenamiento Territorial que constituya el marco normativo para las políticas de ordenamiento territorial del país. 
Se considera que esta ley debe contener cuatro partes fundamentales: Principios, objetivos y directrices de la política territorial nacional; Componentes del Sistema de Ordenamiento Territorial Nacional; Derechos y deberes de los habitantes e Instrumentos de Política Territorial.

Los Principios, basados en la Constitución y pactos internacionales que la integran como: -La función social de la propiedad (inciso 1 del artículo 21 de la Convención Americana sobre Derechos Humanos);-La prevalencia del interés general sobre el particular está vinculada con las limitaciones que se impone a la propiedad en base al interés general (artículo $17 \mathrm{CN}$ y artículo 2.611 del Código Civil);-La distribución equitativa de las cargas y los beneficios del proceso de urbanización se apoya en el principio constitucional a la igualdad (artículo 16 de la $\mathrm{CN}$ ).

Una Ley Nacional de Ordenamiento Territorial con los principios, objetivos y directrices expuestos no puede ser una ley meramente declarativa. Es por ello que se hace necesario definir una serie de instrumentos de política territorial, que permita a las provincias y los municipios contar con herramientas para dar mayor sustento al desarrollo de sus políticas.

Los instrumentos propuestos son: Derecho de preferencia del poder público; Subdivisión parcelaria, edificación o utilización obligatoria; Gravamen especial (al suelo ocioso) progresivo en el tiempo; Contribución por mejoras; Participación de los Municipios en la valorización de inmuebles generados por acciones urbanísticas; Otorgamiento oneroso del derecho de construir; Operación urbana mixta; Reajuste de terrenos; Evaluación de impacto urbano y del entorno; Preservación de ámbitos urbanos, como principios rectores.

Asimismo las políticas de vivienda y hábitat que se implementan se encuentran regidas por los siguientes principios: el derecho a la ciudad y a la vivienda; la función social de la propiedad; la gestión democrática de la ciudad; zonas especiales de interés social y el reparto equitativo de cargas y beneficios de la urbanización. Sobre este último punto recae uno de los problemas que enfrentan los municipios: crecimiento urbano disperso, retención de suelo, presión para lotear en la periferia, demanda por servicios imposible de satisfacer.

La ciudad es un escenario de disputas como advertíamos al inicio del artículo, la gestión territorial se realiza siempre en un contexto de poder compartido, esto supone la existencia de conflictos entre intereses contradictorios y en algunos casos antagónicos. Por lo tanto entre las principales demandas se plantea la construcción e institucionalización de canales de participación y consenso. 


\section{A modo de conclusión}

Las ciudades argentinas han modificado su fisonomía y su configuración territorial, en un principio durante los años noventa con el anclaje del capital financiero y la dinámica privatizadora en los espacios urbanos y posteriormente con la reactivación económica de los últimos años, que ha producido la expansión de la demanda de bienes y particularmente de suelo urbano para desarrollar nuevos usos y actividades.

Se ha tratado el derecho a la ciudad en un sentido amplio, el derecho al habitar y al hábitat digno es esencial para el acceso de los sectores populares al suelo urbano. En este sentido, es primordial promover no solamente un cambio conceptual, sino también una legislación urbanística que permita crear mecanismos para la recuperación y distribución de beneficios extraordinarios como una obligación de las gestiones locales para eliminar las desigualdades urbanas.

En el debate se planteó la necesidad de un conjunto de metodologías alternativas que, basadas en un replanteamiento de las relaciones entre gobierno, territorio y comunidad, permitan diseñar nuevos marcos y escenarios con enfoques de actuación e intervención más democráticas y participativas.

El Estado es el actor fundamental en la definición de políticas públicas y mediante la planificación y organización territorial opera en la esfera política, técnica y de gestión mediante planes, programas y proyectos cuya acción e implementación favorecen la accesibilidad del espacio urbano y al crecimiento controlado de las ciudades.

La disociación entre las esferas técnicas y políticas de nivel nacional, provincial y municipal y la falta de instrumentos normativos de orden jurídico-tributario y de gestión, aplicables al mercado del suelo urbano impide situar los derechos de las personas y el derecho a la ciudad en condiciones de equidad e inclusión.

Las dificultades para obtener el acceso individual o colectivo a los recursos que las ciudades proporcionan, impide la ligazón de los fragmentos urbanos y la integración del tejido social.

La práctica de la gestión y concertación requiere la capacidad de los gobiernos locales de asumir la organización territorial de las ciudades y la necesidad de diseñar políticas y programas con instrumentos públicos que permitan la ampliación de nuevos derechos ciudadanos.

Estos nuevos derechos, al habitar y al hábitat en la ciudad son principios fundantes de la planificación y la gestión urbana pero requieren de la voluntad política de los que llevan adelante esos procesos y el ejercicio de una acción colectiva sobre el proceso de urbanización. 